\title{
Oscillatory Trajectories Applied to NASA's DF-7 Copnfiguration
}

\author{
Gregory E. Moster \\ Air Vehicle Directorate, Air Force Research Laboratory \\ Wright Petterson AFB. Ohio 45433 \\ John G. Martin \\ NASA Langley Research Center \\ Hampton, Virginia 23681
}

AIAA Paper No. 99-4931

Presented at the

AIAA 9th International Space Planes and Hypersonic

Systems and Technologies Conference

November 1-5, 1999

Norfolk, Virginia 


\title{
OSCILLATORY TRAJECTORIES APPLIED TO NASA'S DF-7 CONFIGURATION
}

\author{
Gregory E. Moster* \\ Air Vehicle Directorate, Air Force Research Laboratory, Wright Patterson AFB, OH 45433 \\ John G. Martin \\ NASA Langley Research Center, Hampton, VA 23681
}

\begin{abstract}
$\underline{\text { Abstract }}$
Analyses of oscillating trajectories were performed using the extensively analyzed NASA Dual Fuel Study Vehicle DF-7 that was designed for Mach 10 global reach reconnaissance/strike missions. (This vehicle was later modified to provide a vehicle design capable of both longrange hypersonic cruise and trajectory pull-up for launching an upper stage to deliver payload to orbit.) Study results indicate that oscillating trajectories result in reduced range, high g loading, higher peak heating, and more severe thermal gradients compared to steady-state cruise. These disadvantages plus the operational complexity of turning the engine off and on during each cycle, contribute to make oscillating trajectories undesirable for lifting-body configurations optimized for hypersonic cruise. Additionally, this study shows that technological advances would most likely benefit steady-state cruise trajectories greater than the oscillatory trajectories.
\end{abstract}

\section{$\underline{\text { Introduction }}$}

A Mach 10 cruise airplane study was sponsored by NASA in 1995/1996 to develop an operational global reach vision vehicle design for reconnaissance/strike missions (ref. 1). The configuration matrix eventually converged to a lifting body with a spatulated apex, underslung engines, and rotating wings (pitch control). Both dual-fuel (hydrogen and JP fuel) and all hydrogen fueled designs were established for this configuration space. In a follow-on effort, requirements were developed to establish the

\footnotetext{
"Aerospace Engineer, Member AIAA

"Aerospace Engineer, Senior Member, AIAA

This paper is declared a work of the U.S.

Government and is not subject to copyright protection in the Unites States.
}

Hyper-X vehicle design to provide airframe integrated scramjet flight tests at Mach 7 and 10 to foster this vision airplane. These Hyper- $X$ flight tests will begin in March of 2000.

A later NASA sponsored study established the viability of using a derivative of the vision airplane design in a dual mission role - hypersonic cruise and space launch using the pop-up maneuver (ref. 2). The payload bay was modified to accommodate a 30,000 pound cylindrical upper stage (including a 5,000 pound payload), measuring 10 feet in diameter by 30 feet in length. Also, a linear aerospike rocket was integrated into the fuselage trailing edge to assist with the pull-up maneuver and permit staging at Mach 11 above 280,000 feet (below 1 psf dynamic pressure). For a takeoff gross weight of less than 500,000 pounds, the vehicle attained more than $7,500 \mathrm{~nm}$ range performing the cruise mission while carrying a 10,000 pound payload. The same vehicle was able to deliver 5,000 pounds into an easterly low Earth orbit using the 25,000 pound inertial upper stage via the pop-up maneuver. The predicted performance of this modified, dual role vehicle was very encouraging for either the dual fuel or all hydrogen versions. Recently, a great deal of interest has been generated by the Hypersoar concept (ref. 3) to use oscillatory/periodic trajectories to extend the range of hypersonic airbreathing vehicles. This work attempted to apply oscillatory trajectories to the aforementioned global reach lifting-body class of hypersonic airbreathing vehicles to extend cruise range.

NASA's Dual Fuel Study Vehicle number 7 (DF-7) is a modern hypersonic cruise aircraft design employing the latest technologies in scramjet propulsion, aerodynamics, structures, materials, and subsystems. This vehicle is supported by state-of-the-art high fidelity engineering analysis and may be possible to build within the near future. To achieve maximum range, the DF-7 was optimized to perform a slightly climbing hypersonic cruise profile. This 
study explores the oscillatory trajectory concept as applied to the DF-7 design. Design sensitivities were performed to identify the primary performance drivers. Finally, technological limits and anticipated advances are discussed to provide perspective.

\section{Background}

In 1933 Dr. Eugene Sanger proposed a hypersonic aircraft concept known as Silverbird that was theoretically capable of boosting an 8,000 -lb payload into a low Earth orbit using liquid fueled rockets. After placing the payload into orbit, the vehicle would return to Earth by performing a series of semi-ballistic skips, figure 1. These skips would have large amplitudes at first and then gradually decrease (damped oscillations) until the vehicle makes a conventional gliding landing. A sort of hypersonic cruiser derivative of Silverbird called the Ameriski Bomber was later proposed as a long-range bomber. This bomber would skipglide cruise using periodic rocket burns to maintain speed. Work continued on these Silverbird like concepts through the 60's when they were abandoned due to insufficient thermal protection technology. (ref. 4)

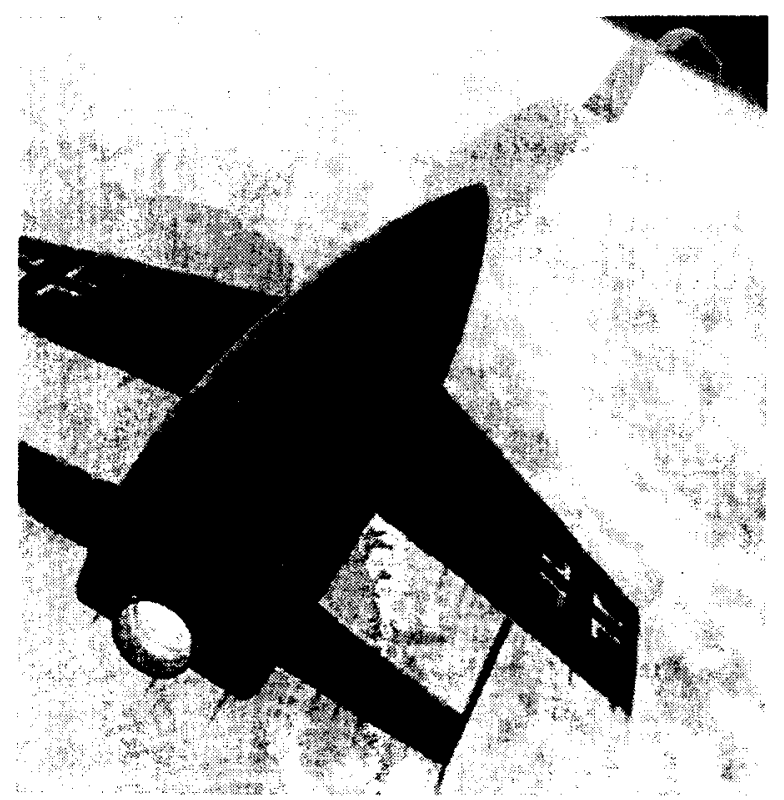

Figure 1. Silverbird

Skip-gliding is a real phenomenon and was later observed during the $X-23 A$ unmanned experimental re-entry vehicle flight tests that occurred over three decades later in 1967. (The $X-24 A$ shown in figure 2 is a manned variant of the smaller unmanned $X-23 A$ ). The skipping event is sinusoidal motion that occurs when flying at very high speeds at a constant pitch angle. Under these conditions, small fight path perturbations result in large altitude variations and therefore large density variations that produce lift modulation. At the time Silverbird was proposed, guidance and navigation technology was not sophisticated enough to perform long range steady-state cruise at hypersonic speeds. Periodic motion was therefore merely an artifact of this limitation in technology.

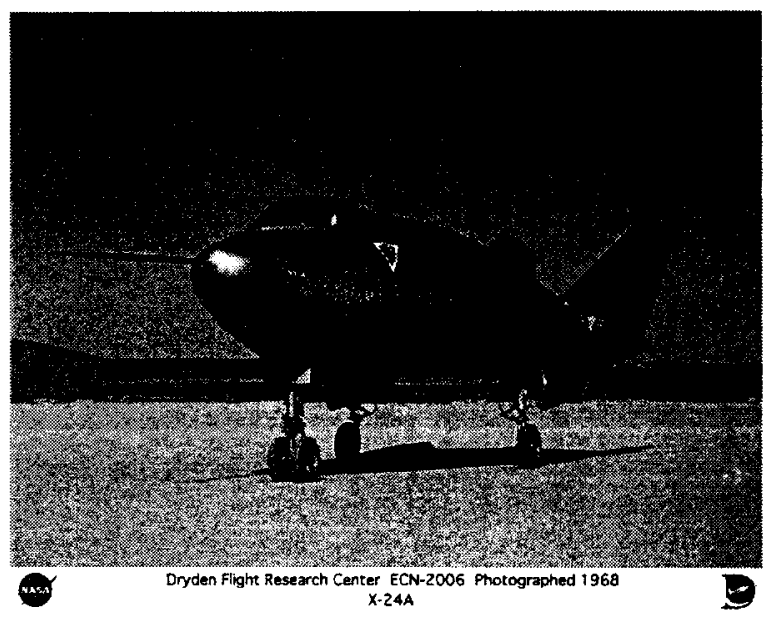

Figure 2. X-24A

\section{Concept}

The oscillating trajectories analyzed in this study consisted of a series of boost-glide cycles powered by airbreathing engines, figures 3 and 4 . After the initial boost, each cycle begins with an unpowered glide phase that is characterized by a constant angle-of-attack ballistic flight. Next, the engines are restarted when dynamic pressure is sufficient to support combustion and a pull-up maneuver begins. Pull-up continues until the vehicle re-establishes the initial altitude, speed, and flight path angle to duplicate the initial conditions. This process is repeated until the cruise fuel is expended and the vehicle makes a powered or unpowered glide to a recovery base.

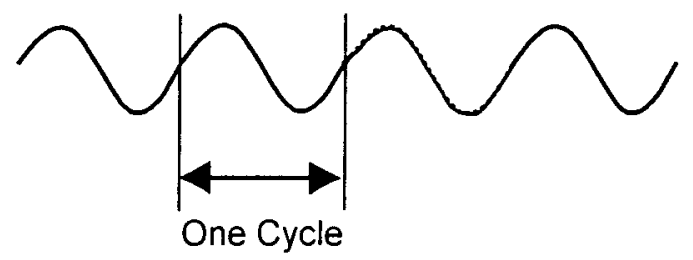

Figure 3. Oscillating Trajectory 


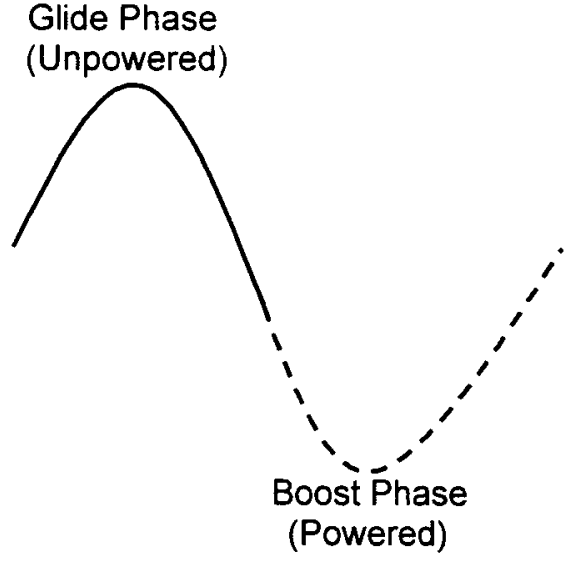

Figure 4. One Cycle

The merit of this concept is based on the expectation that the reduced drag losses incurred during the higher altitude ballistic phase outweigh the additional fuel used to re-accelerate the vehicle every cycle. In other words, the vehicle is expected to burn less fuel overall to achieve the same range. There is also an expectation that the extremely efficient radiative cooling process that occurs at high altitude, during the ballistic glide phase, will outweigh the elevated aerodynamic heating encountered during each dip into the lower atmosphere. This cooling concept was explored for hypersonic airbreathing missile designs with heat-sink engines in reference 5.

\section{Vehicle Model Selection}

Accurate determination of potential benefits of oscillating trajectories over steady state cruise requires a vehicle model of sufficient fidelity and substantiation. NASA's DF-7 configuration was therefore selected. This vehicle has an extensive aerodynamic, propulsive, subsystem, and structural database that can trace its roots to the NASP era. (Propulsion aspects of the database are classified due to its NASP lineage and have been unavailable to previous researchers on this topic.) Although the DF-7 was not designed for oscillating trajectories, it was selected because it was designed to operate at similar flight conditions $(125,000$ feet and Mach 10) as used in recently published hypersonic periodic cruiser studies (ref. 3 ). Thus more direct comparisons with other work done in this area can be made.

\section{$\underline{D F-7}$}

The DF-7 configuration, from the NASA DualFuel study, was the latest result of years of NASA,
Air Force, and industry hypersonic research to arrive at an optimal hypersonic cruise vehicle for military reconnaissance/strike missions (ref. 6). Figure 5 shows the Hyper-X $(X-43)$ experimental aircraft whose geometry is based upon the DF-7 configuration. DF-7 was designed to have a mission radius of 8,500 nautical miles, cruise at Mach 10 at altitudes of over 110,000 feet, have a balanced field length of under 15,000 feet, and carry 10,000 pounds of payload in 2,000 cubic feet of cargo volume. The term dual fuel refers to the use of both hydrogen and hydrocarbon fuels. Hydrocarbon fueled turbojets are employed for low speed (Mach < 4.5) acceleration and subsonic cruise (return leg or ferry). Hydrocarbon fuel also enables in-flight refueling for subsonic operation. The ramjet/scramjet engines that operate from Mach 4 to 10 are fueled with hydrogen. Hydrogen offers much greater cooling capacity beyond Mach 7 than hydrocarbon fuels and better performance. Figure 6 shows the vehicle layout and packaging. The DF-7 performance model was developed using state-of-the-art engineering analysis tools such as SRGULL (ref. 7) and S/HABP (ref. 8) and augmented with CFD analysis. SRGULL is a ramjet/scramjet integrated analysis tool (inlet, combustor, and nozzle) employing experimentally based empirical algorithms.

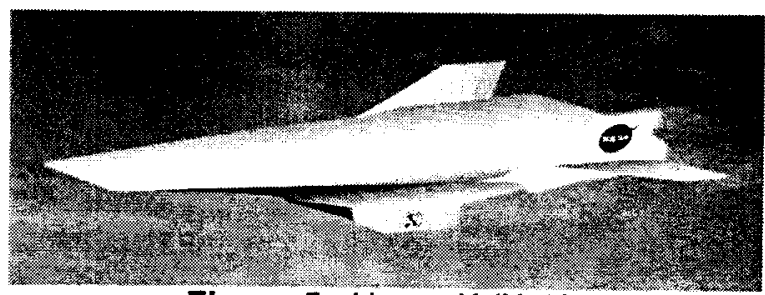

Figure 5. Hyper-X $(X-43)$

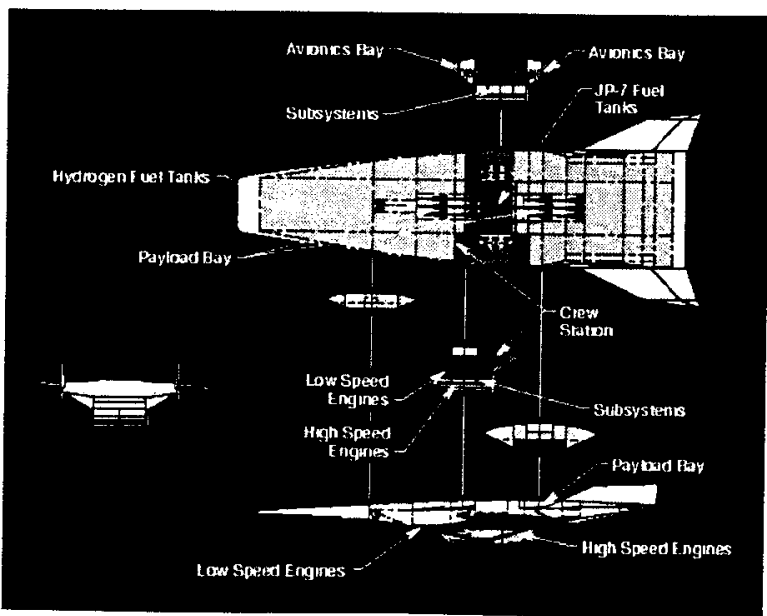

Figure 6. DF-7 Layout. 


\section{Analysis Methods}

All trajectory computations were performed using the 3 Degree-of-Freedom (3DOF) Program to Optimize Simulated Trajectories (POST) program (ref. 9). Options used were: 1972 standard atmosphere, atmospheric relative coordinate system, acceleration-steering using aerodynamic angles, spherical earth model, ramjet engine model and pitch plane static trim using aerodynamic controls. Optimization was extensively applied throughout using the NPSOL optimizer option in POST.

\section{Simulation Constraints}

Constraints were imposed on the propulsion system operation and trajectory. Propulsion system constraints were minimum fuel equivalence ratio and engine-on/off dynamic pressure. The minimum fuel equivalence ratio constraint is governed by the minimum fuel flow required for all actively cooled engine and airframe surfaces. Actual minimum values for the DF-7 are higher than the ones used in these simulations; however, the lower value provides oscillating trajectories greater latitude and may reflect far term technology advances. Minimum dynamic pressure for scramjet engine operation is governed by combustor dynamics that are geometry dependent and are a function of angle of attack and flight conditions. Because there is no database to determine exactly where these engines will flameout or re-light, dynamic pressures at which these phenomena occur were estimated and used as engine on/off moding criteria. Finally, a sensitivity analysis was performed to determine which design and mission variables have the greatest impact on range.

Each cycle of an oscillatory cruise trajectory must begin and end at the same flight conditions. Trajectory constraints include the initial and final values for: velocity, altitude and flight path angle (gamma). Matching these conditions permit the vehicle's flight path to smoothly transition from one cycle to the next and perform an oscillatory trajectory. These assumptions are not perfect because the vehicle's weight continues to change; however, they are sufficient for this study.

Finally, a nominal load limit of $2.5 \mathrm{~g}$ 's was later imposed to determine the impact on range. This limitation was imposed because it was a DF-7 structural design limitation and it is a realistic limit for a hypersonic vehicle of this size.

\section{Simulation Objective Function}

The main objective of this study was to quantify the range advantage of periodic trajectories for the NASA Mach 10, global reach class of hypersonic airbreathing vehicles. This was accomplished by optimizing the range per pound of fuel consumed over one repeatable cycle or period. Range per pound of fuel represents cruise efficiency and can be multiplied by the amount of cruise fuel to approximate the total vehicle's cruise range. This method provides a value of relative merit.

\section{Vehicle Model Modification}

Modifications were required to the vehicle model because the unpowered glide phase requires either engine-off flow-through aerodynamics or inlet cowl door closed aerodynamics. Cowl door closed aerodynamics was selected because the inlet-open operation requires a significant amount of fuel to cool critical engine components exposed to Mach 10 flow enthalpy and adds a large aerodynamic penalty. Also, closed cowl door aerodynamics would provide a small amount of additional lift. The closed cowl door aerodynamic adjustments were derived from the Hyper- $X$ database and should be representative of actual values for the DF-7.

\section{Fundamental Understanding}

This study focused primarily on a single oscillatory cycle. A detailed understanding of how the vehicle responds to constantly changing aerodynamic forces is critical if the advantages and disadvantages are to be identified. For this discussion we will focus on the 10 degrees of flight path angle case with the study baseline parameters of Mach 10 and 125,060 feet altitude.

The glide phase depicted in figure 7 is characterized by the exchange of altitude for airspeed as illustrated in figure 8 . Upon engine flameout, the cowl door is closed and the vehicle begins the ballistic mode of flight. After the maximum altitude is reached, the vehicle begins to descend and accelerate. Once sufficient dynamic pressure is the reached, the engines are restarted, and the boost phase begins.

The velocity curve shown in figure 8 makes an interesting hook at approximately 160 seconds. This deceleration is caused by the aerodynamic drag build-up that occurs as the dynamic pressure rises due to increasing atmospheric density. 
The boost phase shown in figure 9 begins when the engines are restarted and the vehicle begins a pull-up maneuver. This pull-up

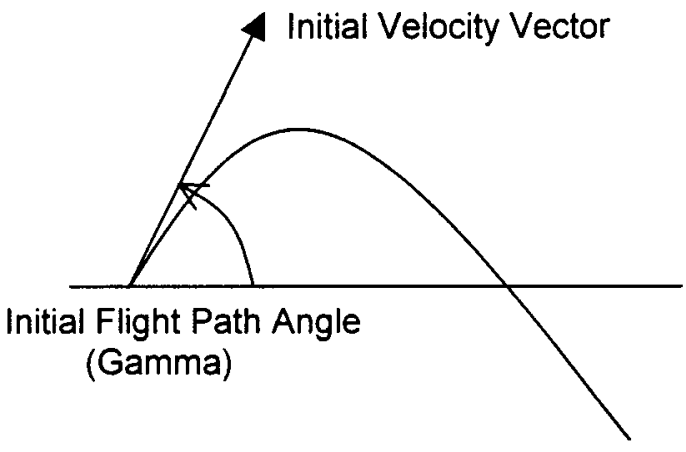

Figure 7. Glide Phase

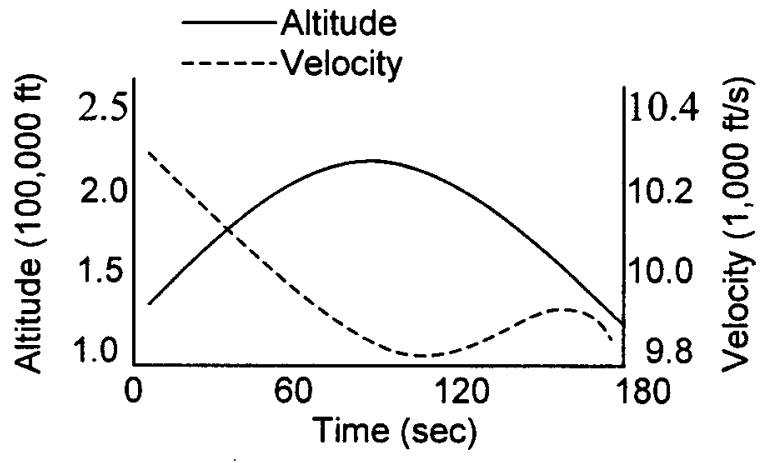

Figure 8. Glide Phase Profile

maneuver continues until the vehicle reestablishes the conditions that existed at the beginning of the glide phase (altitude, airspeed, and flight path angle). At this point the engines are turned off and a new cycle begins. The boost phase must restore the vehicles kinetic and potential energy lost during the glide phase. Greater demands are imposed upon the vehicle during boost as compared to steady-state cruise. Accelerating

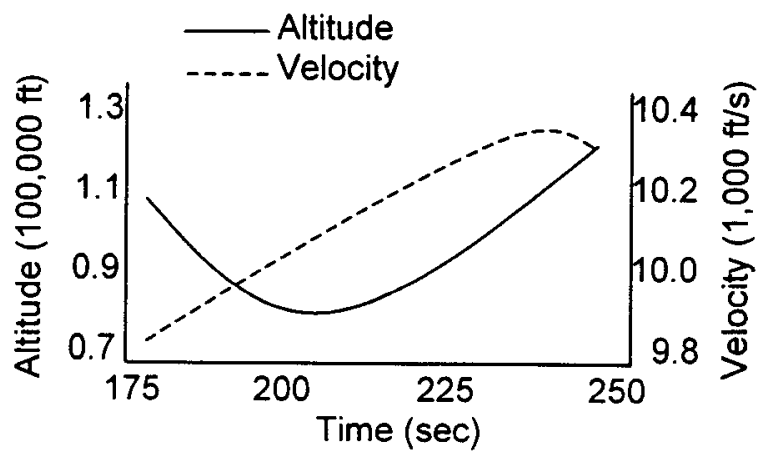

Figure 9. Boost Phase Profile while performing a pull-up maneuver increases the induced drag losses and therefore fuel consumption. Also, structural loading increases rapidly as the initial flight path angle (see figure 7) increases.

All analysis in this study includes pitch-plane trim effects and engine-off/inlet-closed aerodynamic increments. The significance of engine-off aerodynamic adjustments can be seen in figure 10. Here, a notional comparison between engine-on and engine-off aerodynamics is illustrated. The cowl-to-tail aerodynamic and propulsion force accounting system defines the solid lines in this figure as aerodynamic surfaces and the dashed lines as propulsion surfaces. Aerodynamic drag is the integration of surface pressure minus freestream static pressure over the aerodynamic surfaces plus friction forces and resolved in the freestream velocity vector direction. Lift is the force resolved perpendicular to drag. Propulsion forces (thrust and propulsive lift) are determined in the same manner using the propulsion surfaces. (Note that zero thrust implies freestream static pressure on the propulsion surfaces and not zero pressure.)

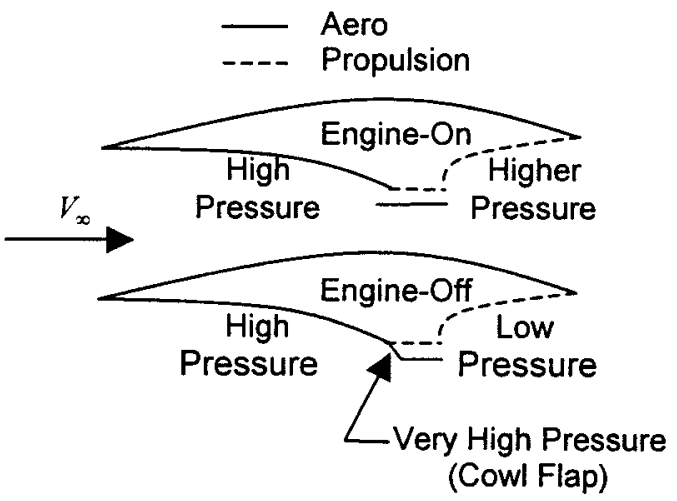

Figure 10. Engine-On/Off Pressure Drag

With the engine on, the forebody is exposed to high pressure (relative to freestream static) whereas the nozzle and propulsion surfaces are subjected to even higher pressure as depicted in the top of figure 10. When the engine is turned off, the inlet cowl flap is closed (as discussed earlier,) exposing the flap to very high pressure which creates a substantial drag adjustment. (Lift also changes, but at a much smaller percentage.) Another contributor to the aerodynamic adjustment is the low pressure (below freestream static) that occurs on the propulsion surfaces when the engine is off. This drag (negative thrust) and lift force increment is determined in the same manner 
as aerodynamic and propulsion forces. Finally, there is a significant change in pitching moment due to these factors, resulting in additional trim drag.

The engine-off trim drag may be excessive for this vehicle because the nozzle was designed for continuous engine operation. Redesigning the nozzle could mitigate this penalty and would be essential for an oscillatory aircraft to achieve maximum performance. However, there may be limited payoff because there would always be a significant difference between engine-on and engine-off pitching moment. Finally, the cowl flap was not designed to provide minimum drag in the closed position, offering additional improvement potential.

\section{Simulation Results}

All trajectories in this study began at Mach 10 , 125,060 feet altitude (unless otherwise indicated), and at the desired flight path angle (gamma). Gamma was parametrically varied from zero to twenty degrees to capture all probable oscillatory profiles. Constraining gamma to zero yields a steady-state constant altitude cruise profile.

The objective was to maximize cruise range for oscillatory trajectory profiles as defined by the start-of-cycle flight path angle (gamma). Cruise range results are presented in figure 11. The dashed line represents the range achieved by neglecting the engine-off aerodynamic penalties whereas the solid line reflects the range obtained when these aerodynamic penalties are included. Imposing a structural normal load limit of $2.5 \mathrm{~g}$ 's results in the cruise range represented by the dotted line.

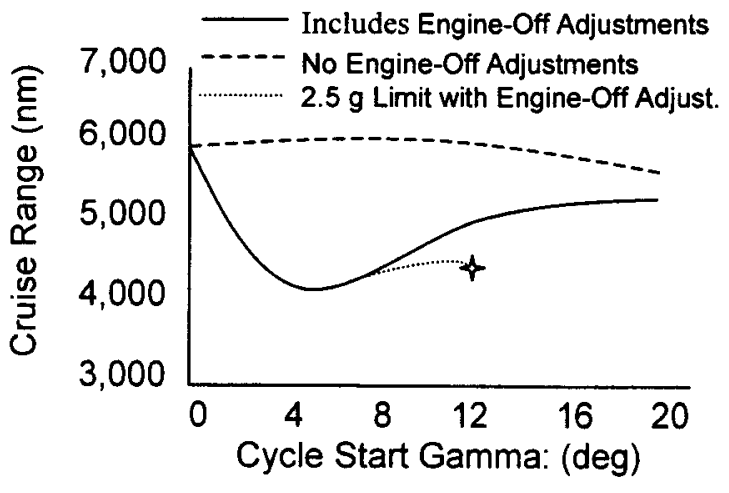

Figure 11. Cruise Range.

The "No Engine-Off Adjustments" curve has a slight upward curve that peaks with a $1.8 \%$ range increase. This curve neglects all drag penalties incurred when the engines are off and places an upward bound on range possibility.

Incorporation of the engine-off aerodynamic adjustments initially causes the range to drop off sharply, as gamma increases, with an eventual rebound and convergence with the "No Engine-Off Adjustment" curve. However, this convergence occurs at excessively large gamma's.

Applying a $2.5 \mathrm{~g}$ normal load limit to the "Engine-Off Adjustment" case yields the final curve represented by the dotted line. Imposing this limit reduces the rebound in range beyond 6 degrees gamma, and causes dramatic reductions in range past 11 degrees gamma. Solutions beyond 11 degrees were not pursued because the range curve was dropping quickly and solutions were difficult to obtain.

Two observations can be made from figure 11. First, significant reductions in cruise range occur when engine-off aerodynamic penalties and structural load limitations are imposed on a vehicle originally designed for steady-state cruise. Second, limited range improvement is achieved over steady-state cruise even if no engine-off penalties or structural load limits are imposed.

Next, a sensitivity study was performed in an attempt to improve cruise range performance. Sensitivities were conducted for lift, drag, weight, and center of gravity position as illustrated in figures 12, 13, 14, and 15, respectively. All four plots show that steady-state trajectories are more sensitive to variations in these parameters than oscillatory trajectories. This is a double-edged sword. It means that steady-state cruise vehicles derive greater benefit from technological advances. However, it also means that oscillatory trajectory vehicles are less sensitive to growth in

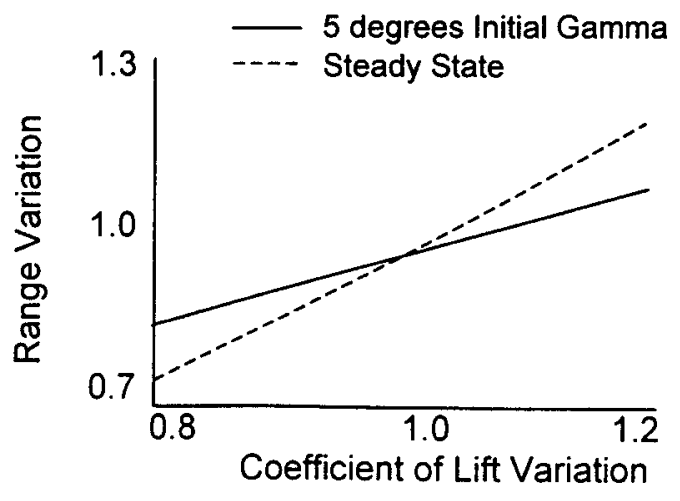

Figure 12. Lift Sensitivity

such things as weight and drag that typically occurs throughout the vehicle development phase. 


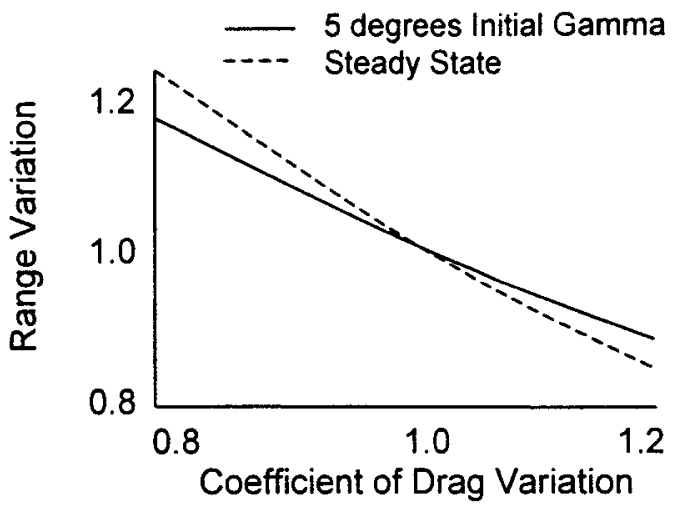

Figure 13. Drag Sensitivity

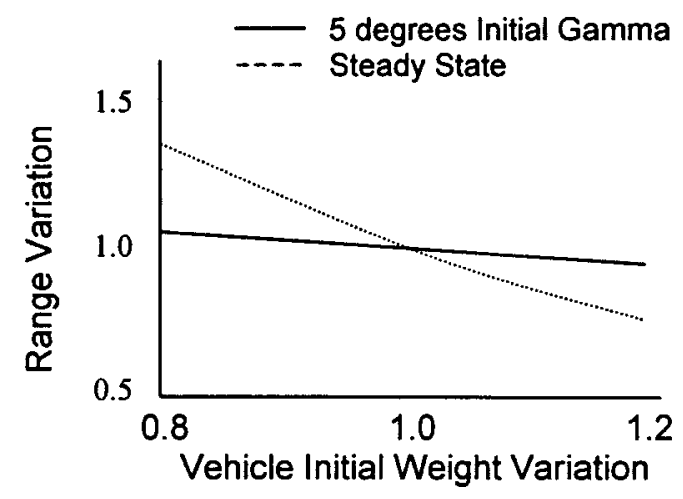

Figure 14. Weight Sensitivity

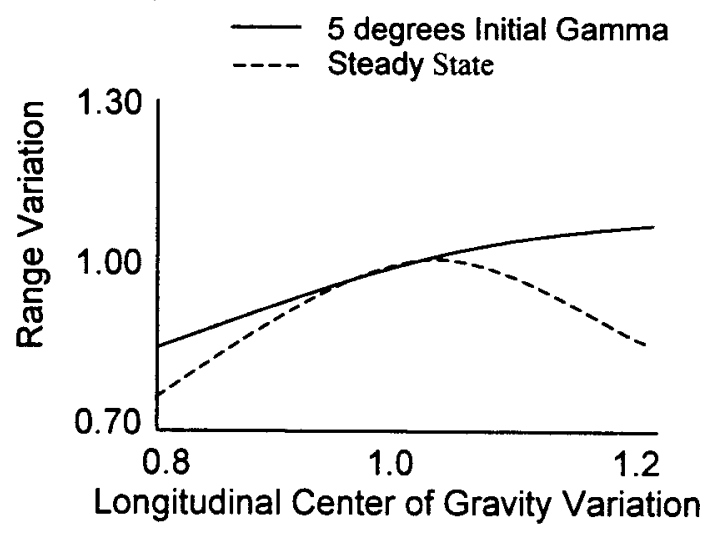

Figure 15. Center of Gravity Sensitivity

Reducing thermal protection system (TPS) requirements was cited as a potential benefit of oscillatory trajectories due to the high radiative cooling rates possible in the upper atmosphere. This can be explored through comparisons of peak heating rates.

For simplicity, relative laminar and turbulent convective heating rates were approximated by equations 1 and 2, respectively (ref. 11). Peak heating rates normally occur in areas of turbulent

$$
\begin{aligned}
& \mathrm{q}_{\mathrm{w}} \propto \mathrm{q}_{\mathrm{o}}^{1 / 2} \mathrm{~V}_{\mathrm{o}}^{3 / 2}=\left(\rho_{\mathrm{o}}{ }^{1 / 2} \mathrm{~V}_{\mathrm{o}}^{5 / 2}\right) / 2 \\
& \mathrm{q}_{\mathrm{w}} \propto \mathrm{q}_{\mathrm{o}}^{4 / 5} \mathrm{~V}_{\mathrm{o}}^{6 / 5}=\left(\rho_{\mathrm{o}}^{4 / 5} \mathrm{~V}_{\mathrm{o}}^{3}\right) / 2
\end{aligned}
$$

flow and usually drive the active cooling system design and the heaviest sections of the passive thermal protection system. The turbulent heating method will therefore be used in the following comparisons. Figure 16 shows the relative turbulent peak heating rates for the zero, five, and ten degrees gamma cases. Relative peak rates of approximately one, three, and six times are shown for the zero, five, and ten degrees gamma cases, respectively. Clearly, active cooling system requirements will significantly increase with oscillatory trajectories. The passive thermal protection system must also be designed to withstand higher thermal gradients and cycling. These results imply a potentially heavier and more costly thermal protection system.

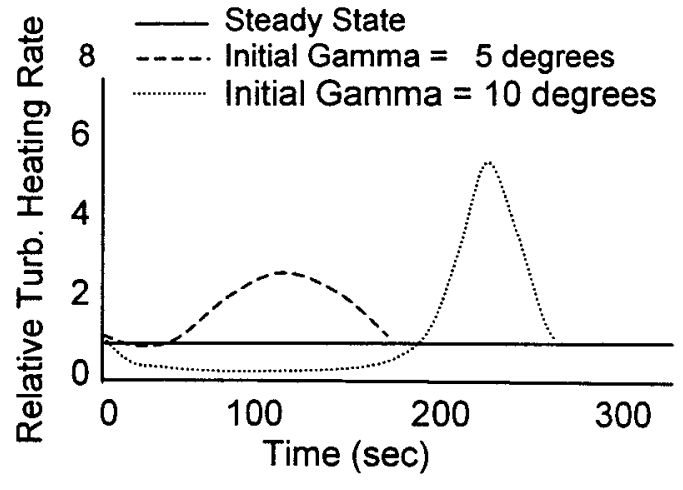

Figure 16. Turbulent Heating Profile

Next, an attempt was made to identify trends for possible exploitation to improve oscillatory cruise range. This was accomplished by plotting various trajectory parameters versus gamma. These parameters include engine-off time, cycle duration, minimum and maximum altitude, minimum and maximum velocity, minimum and maximum dynamic pressure, glide phase angle of attack, cycle range, and normal loading, as seen in figures 17 through 23 . These curves show a definite consistency. First, as expected, cycle range increases (above 4 degrees gamma) as engine-off duration becomes a greater proportion of total cycle duration, figure 17. Second, the maximum velocity and minimum dynamic pressure do not vary much as gamma increases; however, the maximum altitude, minimum velocity and maximum dynamic pressure do. Third, the 


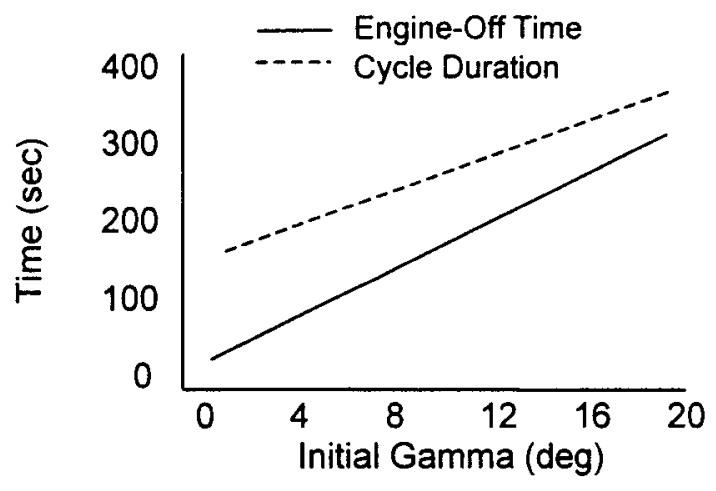

Figure 17. Engine-Off and Cycle Time

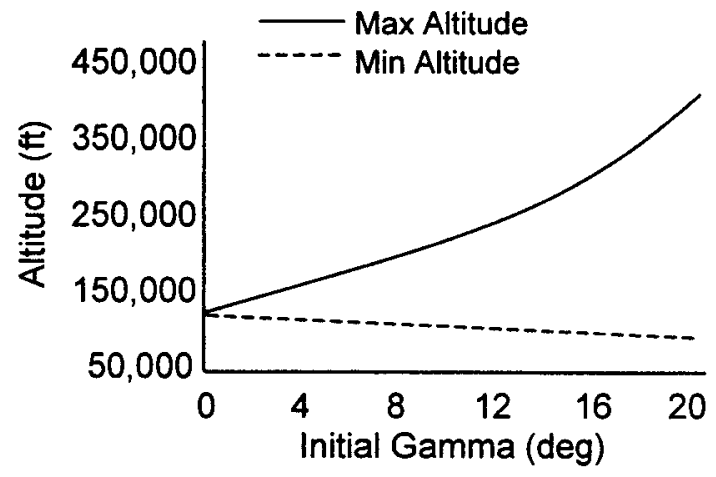

Figure 18. Altitude

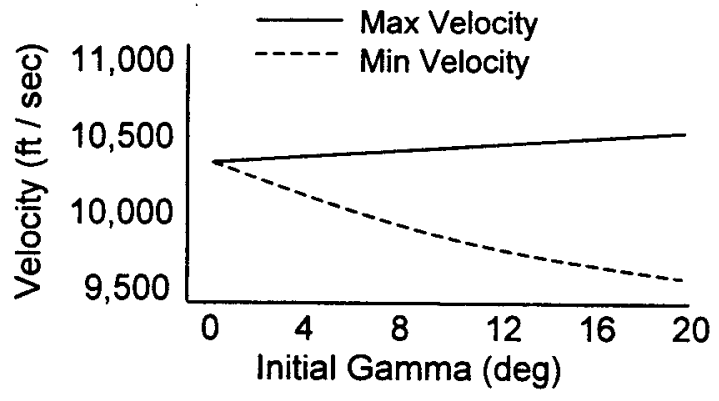

Figure 19. Velocity

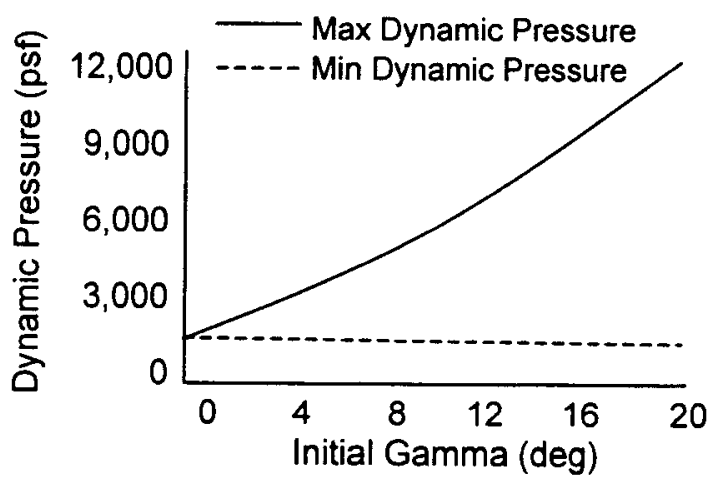

Figure 20. Dynamic Pressure.

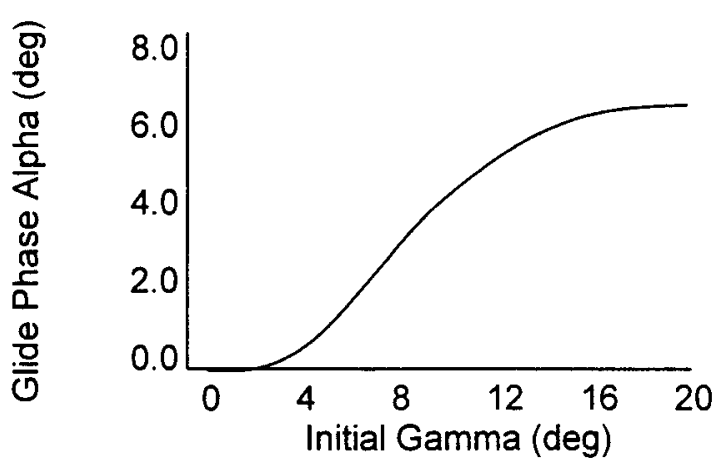

Figure 21. Glide phase angle of attack

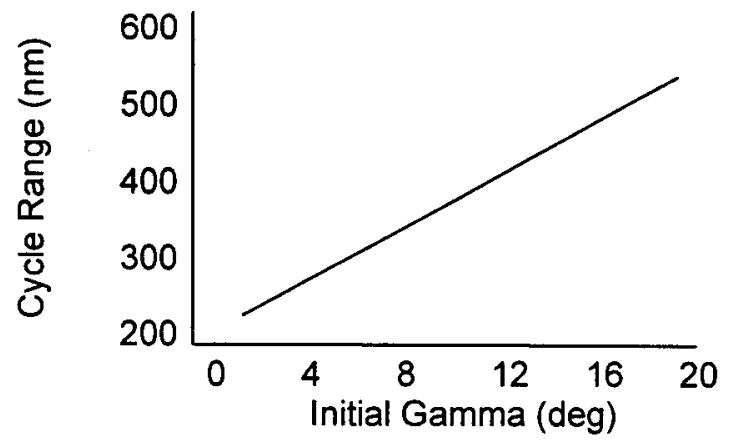

Figure 22. Cycle range

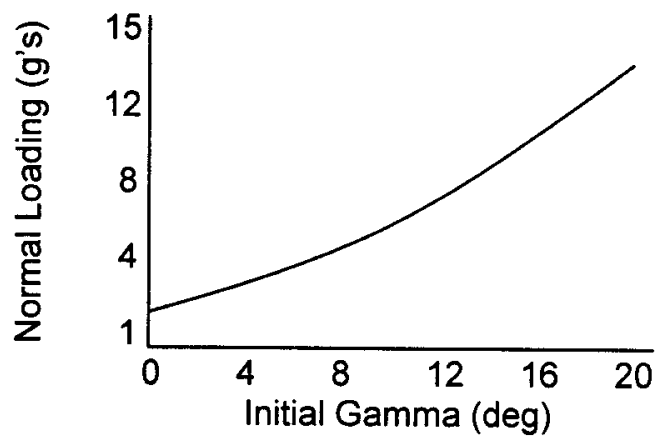

Figure 23. Peak Normal Loading

unconstrained peak normal loading curve, figure 23, shows load consistently increasing as the start-of-cycle (initial) flight path angle increases.

Finally, the altitude, velocity, and drag time histories are plotted for one complete cycle for the 5 and 10 degrees gamma cases and compared to steady-state results in figures 24,25 , and 26 , respectively. These plots show that higher gamma (gamma > 5) trajectories result in the vehicle spending more time at higher altitudes and lower velocities (lower dynamic pressure), diminishing the impact of the engine-off drag penalties. 


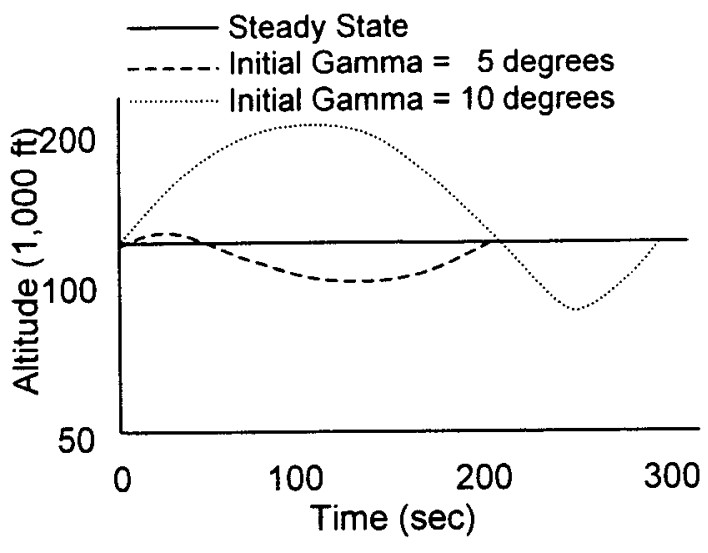

Figure 24. Altitude Profile

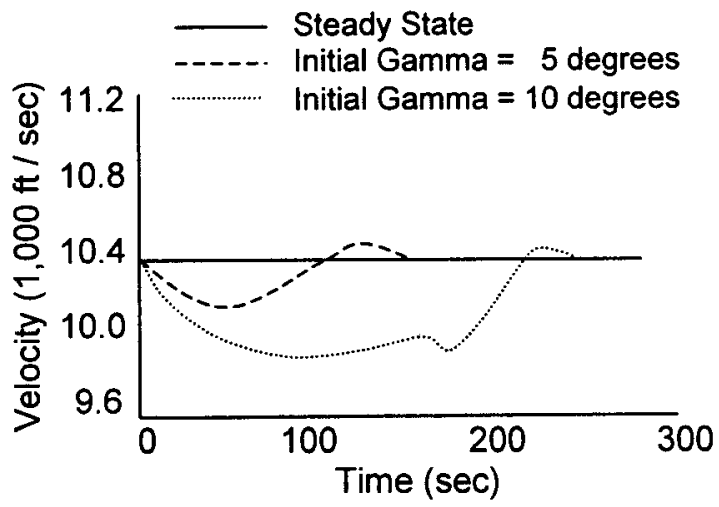

Figure 25. Velocity Profile

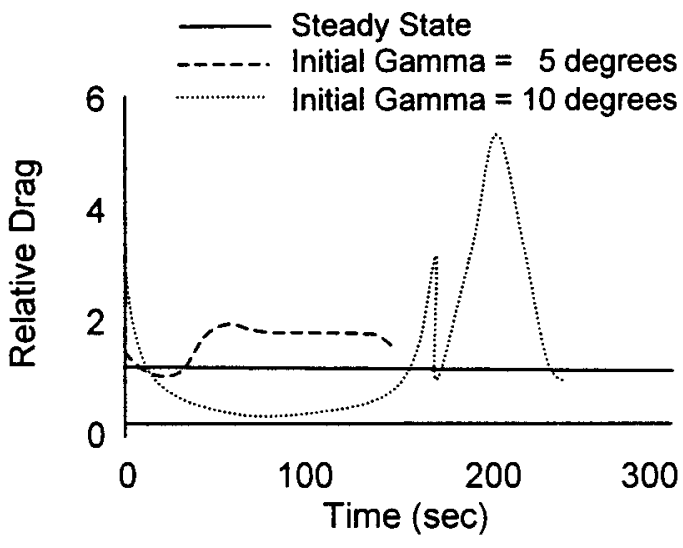

Figure 26. Drag Profile

\section{Summary and Conclusions}

Oscillatory trajectories were evaluated for the lifting-body class of hypersonic airbreathing cruise vehicles using the NASA Mach 10 Dual-Fuel Study global reach vehicle design, DF-7. Cruise range was compared against steady-state cruise results using the same vehicle model. Performance model modifications were necessary to enable the vehicle to perform oscillatory trajectories. Namely, aerodynamic adjustments were required to properly model the engine-off operating mode. Results were not very encouraging however. Range dropped off dramatically as oscillatory motion was introduced, with reductions approaching 30 percent in some cases. Optimizing the vehicle for oscillatory missions would help mitigate the engine-off aerodynamic penalties and increase range. There will always, however, be fairly significant differences between engine-on and engine-off aerodynamic characteristics for this class of vehicles. Having said that, it seems unlikely that oscillatory trajectories can offer any range advantage over steady-state cruise. Moreover, the sensitivity study did not reveal any potential improvement advantage compared to steady-state cruise. Other areas of concern include excessive normal loading during the pull-up maneuver for the higher gamma cycles, higher peak heating rates and repeated thermal and mechanical cycling.

There may be other configuration classes that can engender the potential improvements that have been suggested for hypersonic oscillatory cruise. There are also other beneficial applications of oscillatory flight that include the access to space pop-up mission. In this scenario, range is not as important as altitude and speed of the initial pullup and glide phases (followed by another pull-up and a gliding descent.) A DF-7 class vehicle with rocket engines added may be able to employ oscillatory like motion to accomplish this task. There have been studies that indicate that this may be successful with the proper constraints on vehicle heating and maneuver loading.

\section{$\underline{\text { References }}$}

1. Bogar, T. J., Eiswirth, E. A., Couch, L. M., Hunt, J. L., and McClinton, C. R., Conceptual Design of a Mach 10, Global Reach

Reconnaissance Aircraft, Paper No. 96-2894, 32 ${ }^{\text {nd }}$ AIAAJASME/AE/ASEE Joint Propulsion Conference, Lake Buena Vista, FL July 1996. 2. Scuderi, L. F., Orton, G. F., Hunt, J. L., Mach 10 Cruise / Space Access Vehicle Definition, Paper No. 98-1584, $8^{\text {th }}$ International AIAA Space Plane and Hypersonic Systems and Technologies Conference, Norfolk VA, April 1998.

3. Carter, P. H., Pines, D. J., and Rudd, L. V., Approximate Performance of Periodic Hypersonic Cruise Trajectories for Global Reach, Paper No. 
98-1644, $8^{\text {th }}$ International AIAA Space Plane and Hypersonic Systems and Technologies

Conference, Norfolk VA, April 1998.

4. Jenkins, D. R., Space Shuttle, Marceline, Walsworth Publishing Company, 1997.

5. Hunt, J. L., Lawing, P. L., Marcum, D. C., and Cubbage, J. M., Conceptual Study of Hypersonic Airbreathing Missiles, Paper No. 78-6, AlAA $16^{\text {th }}$ Aerospace Sciences Meeting, Huntsville AL, January 1978.

6. Bogar, T. J., Alberico, D. B., Johnson, D. B., Espinosa, A. M., and Lockwood, M. K.,Dual-Fuel Lifting Body Configuration Development, Paper No. 96-4592, $7^{\text {th }}$ International AIAA Space Plane and Hypersonic Systems and Technologies Conference, Norfolk VA, November 1996. 7. Pinckney, S. Z., and Walton, J. T., Program SRGULL: An Advanced Engineering Model for the Prediction of Airframe-Integrated Subsonic/Supersonic Hydrogen Combustion Ramjet Cycle Performance, NASA TM 1120, January 1991.

8. Gentry, A. E., et. al., The Mark IV Supersonic/Hypersonic Arbitrary Body Program, AFFDL-TR-73-159, November 1973.

9. Brauer, G. L., et. al., Program to Optimize Simulated Trajectories (POST), NASA Contract NAS1-18147, September 1989.

10. Regan, F. J. and Anadakrishnan, Dynamics of Atmospheric Re-Entry, AIAA Education Series, Published by AIAA, 1993, pp. 389-398.

11. Heiser, W. H., and Pratt, D. T., Hypersonic Airbreathing Propulsion, AIAA Education Series, 1994. 